\title{
Role of Ammonia Secretion and pH Modulation on Pathogenicity of Colletotrichum coccodes on Tomato Fruit
}

\author{
N. Alkan, ${ }^{1}$ R. Fluhr, ${ }^{2}$ A. Sherman, ${ }^{3}$ and D. Prusky ${ }^{1}$ \\ ${ }^{1}$ Department of Postharvest Science of Fresh Produce, Agricultural Research Organization, the Volcani Center, \\ Bet Dagan 50250, Israel; ${ }^{2}$ Department of Plant Sciences, Weizmann Institute of Science, Rehovot, Israel; ${ }^{3}$ Department \\ of Genomics, Agricultural Research Organization, the Volcani Center, Bet Dagan 50250, Israel
}

Submitted 9 November 2007. Accepted 1 April 2008.

Colletotrichum coccodes was found to alkalinize the decaying tissue of tomato fruit via accumulation and secretion of ammonia. Alkalinization dynamics caused by ammonia secretion from growing hyphae was examined microscopically using the pH-sensitive fluorescent dye $2^{\prime}, 7^{\prime}$-bis(carboxyethyl)-5(6)-carboxyfluorescein. Values of pH of 7.9 observed in the host tissue close to the hyphal tips declined to $\mathrm{pH} 6.0$ at $10 \mathrm{~mm}$ away from the hyphal tip, which was a value that was still higher than that detected in the healthy tissue, pH 4.2. Ammonia accumulation at the infection site depended on the initial environmental $\mathrm{pH}$. Treatments with low (4.0) $\mathrm{pH}$ buffer at the infection site resulted in high levels of ammonia secretion and increased virulence of $C$. coccodes compared with similar treatments with buffer at $\mathbf{p H}$ 7.0. Significantly, mutants of $C$. coccodes defective in nitrogen utilization, nit $^{-}$, and are $^{-}$were impaired in ammonia secretion and showed reduced decay development. The reduced infection rate of nit mutants could be complemented by adding glutamine at the infection site. Thus, ammonia accumulation is a critical factor contributing to $C$. coccodes pathogenicity on tomato fruit. The results show that the initial acidic pH of the fruit is conducive to ammonia secretion and the subsequent alkalinization of the infection site, and facilitates fungal virulence and the transformation from the quiescent-biotrophic to active-necrotrophic state.

Alkalinization of the fruit host environment during colonization by postharvest pathogens such as Colletotrichum and Alternaria spp. is associated with fungal secretion of ammonia (Eshel et al. 2002; Prusky et al. 2001). Ammonification of the host tissue has been suggested to be a key factor in the enhancement of Colletotrichum pathogenicity due to activation of pathogenicity factors; for example, the secretion of pectate lyase (Kramer-Haimovich et al. 2006). Consequently, it is thought to be crucial for successful transformation from the quiescent stage to an active colonizing infection, although direct evidence for this is still lacking.

Natural changes in fruit host $\mathrm{pH}$ and nitrogen content have been suggested as possible signals activating the initiation of ammonia secretion. In avocado, the pericarp of freshly harvested fruit showed a $\mathrm{pH}$ of 5.2 that increased to between 7.5 and 8.0 during Colletotrichum gloeosporioides attack (Yakoby et al. 2000). In tomato fruit, the initial $\mathrm{pH}$ ranged between 4.1

Corresponding author: D. Prusky; Telephone: +1-972-3-9693880; Fax: +1-972-3-9683622; E-mail: dovprusk@agri.gov.il and 4.5, decay development at the infection site increased the $\mathrm{pH}$ to 8.0 , and ammonia accumulated to $3.6 \mathrm{mM}$ compared with levels of $0.2 \mathrm{mM}$ in control tissue (Prusky et al. 2001). Yakoby and associates (2001) suggested that $\mathrm{pH}$ modulates the regulation of gene expression of key virulence factors, such as pelB encoding for pectate lyase. This regulation ensures that pathogenicity-protein factors with $\mathrm{pH}$-sensitive activity optima are activated only under the environmental conditions in which they function most effectively.

Thus, $\mathrm{pH}$ should be considered as an initial signaling component and, at the same time, as the milieu necessary for optimal fungal growth. However, a temporal differentiation of these components has never been carried out. In addition to $\mathrm{pH}$, nitrogen availability has also been suggested as a regulatory factor for colonization of phytopathogenic fungi (Coleman et al. 1997; Snoeijers et al. 2000; Stephenson et al. 1997; Talbot et al. 1993; Van den Ackerveken et al. 1994). Although fungi can utilize a wide range of nitrogen sources, ammonia and glutamine are preferred. When these primary sources are present in low concentrations, other secondary sources can be used (Marzluf 1997). Nitrogen assimilation in fungi produces ammonia that is either further metabolized by the fungus or secreted via specific outward transporters (Guaragnella and Butow 2003; Marzluf 1997). The utilization of a variety of nitrogen sources is highly regulated by a catabolite repression factor represented by areA/nit2 (Arst and Cove 1973; Fu and Marzluf 1990). Many areA/nit2 orthologs have been cloned and characterized. Disruption of the area/nit 2 ortholog Clnrl in $C$. lindemuthianum had a severe effect on pathogenicity, compromising the infection cycle at the stage of secondary hyphal formation and almost completely eliminating the formation of anthracnose symptoms in Phaseolus vulgaris (Pellier et al. 2004). In contrast, nutritional-adaptation of $\operatorname{are}^{-}$homolog mutants in Fusarium oxysporum affect expression of genes involved in organic-nitrogen acquisition, mainly during early phases of infection (Divon et al. 2005), suggesting the importance of nitrogen regulation at a particular life stage of this pathogen.

The objective of the present work is to directly examine the contribution of $\mathrm{pH}$ and ammonia accumulation to the pathogenicity of $C$. coccodes in tomato fruit. $C$. coccodes colonizes living host tissue asymptomatically, and the production of signs and symptoms of infection are delayed until senescence occurs. The strategy of the hemibiotrophic species commences from a transient post-penetration asymptomatic biotroph that is followed by a more destructive necrotrophic stage (Latunde-Dada 2001). Using exogenic $\mathrm{pH}$ modulation of the C. coccodes infec- 
tion site, it was shown that the infection rate is determined by the initial $\mathrm{pH}$ and the total accumulation of ammonia. Furthermore, nit $^{-}$and are $^{-}$mutants with reduced capability for ammonia accumulation are compromised in their pathogenicity on tomato fruit. The results suggest a key role of ammonia accumulation as a pathogenicity factor during attack by Colletotrichum spp. that induces transformation of the biotrophic to a necrotrophic infection to the initiation of postharvest decay.

\section{RESULTS}

Effect of pH on alkalinization, ammonification, and decay development in tomato tissue during colonization by $\boldsymbol{C}$. coccodes.

We wished to establish an experimental system that could evaluate the fungal behavior in pathogen-fruit interactions. A circular, 10-mm-diameter epidermal tomato fruit disc was removed and inoculated with a hyphal mat grown under specified conditions (described below). This provided us with a homogeneous synchronized infection front and facilitated in situ measurements and the addition of exogenous material in the exposed infection zone. Inspection of the infection front with a $\mathrm{pH}$ probe showed that, after 2 days, the $\mathrm{pH}$ of the infection center was 7.9 whereas the $\mathrm{pH}$ in the uninfected fruit tissue was 4.2. Using the $\mathrm{pH}$-indicator stain $2^{\prime}, 7^{\prime}$-bis(carboxyethyl)5(6)-carboxyfluorescein (BCECF), a sharp decrease of $1.9 \mathrm{pH}$ units was detected in the extracellular spaces within $10 \mathrm{~mm}$ of the hyphal front (Fig. 1A and B). These results demonstrated that rapid $\mathrm{pH}$ changes indicative of the diffusion of an alkalinizing molecule by $C$. coccodes colonization can be detected in pre-peeled fruit.

The low $\mathrm{pH}$ in fruit is thought to be suboptimal for Colletotrichum spp. attack due to inhibition of tissue-macerating enzymes (Yakoby et al. 2001). However, the possibility that low $\mathrm{pH}$ plays a desirable initial role by enhancing the capacity of the fungus to activate ammonia secretion was not examined earlier. Therefore, we examined the response of ammonia secretion in $C$. coccodes to the initial fruit $\mathrm{pH}$ by maintaining the infection site at a specified $\mathrm{pH}$ of 4.0 or 7.0 with exogenous application of $50 \mathrm{mM}$ phthalate buffer. The tissue was examined 2 days later. In situ hyphae treated with buffer at $\mathrm{pH} 4.0$ showed higher BCECF fluorescence localized to inside the hyphae than hyphae treated with buffer at $\mathrm{pH} 7.0$ (Fig. 2A). This phenomenon observed at $\mathrm{pH} 4.0$ was correlated with a 3fold increase in external ammonia accumulation (Fig. 2B) and a 1.5-fold increase in the rate of decay compared with $\mathrm{pH} 7.0$ (Fig. 2C). Inoculated and untreated tomato fruit with a $\mathrm{pH}$ of 4.2 showed ammonia accumulation and decay development similar to that of the inoculated fruit treated with buffer at $\mathrm{pH}$ 4.0 (Fig. 2). Wounding of noninoculated fruit treated with buffer at either $\mathrm{pH} 4.0$ or 7.0 did not show any ammonia accumulation and the internal $\mathrm{pH}$ did not change. The results suggested that the lower $\mathrm{pH}$ stimulates significant ammonia synthesis and secretion in the hyphae which is conducive to enhanced host colonization.

To examine whether the internal $\mathrm{pH}$ enhancement was due to ammonia accumulation, a similar experiment was conducted in vitro. $C$. coccodes was subcultured on secondary media at pH 4.0 or 7.0 (Fig. 3). Ammonia did not accumulate in the culture medium when the initial $\mathrm{pH}$ was 7.0. However, within 22 $\mathrm{h}$ of exposure to media at an initial $\mathrm{pH}$ of 4.0, ammonia at 134 $\mathrm{mmol} / \mathrm{g}$ of fresh weight (FW) accumulated and elevated environmental $\mathrm{pH}$ by 2.1 units (Fig. 3). These results demonstrated rapid induction in situ and in vitro of ammonia accumulation in the presence of low $\mathrm{pH}$.

\section{Isolation of nit $^{-}$and are $^{-}$mutants.}

The above results suggested that conditions stimulating ammonia accumulation by the pathogen may lead to enhanced host colonization. To directly demonstrate the host colonization-
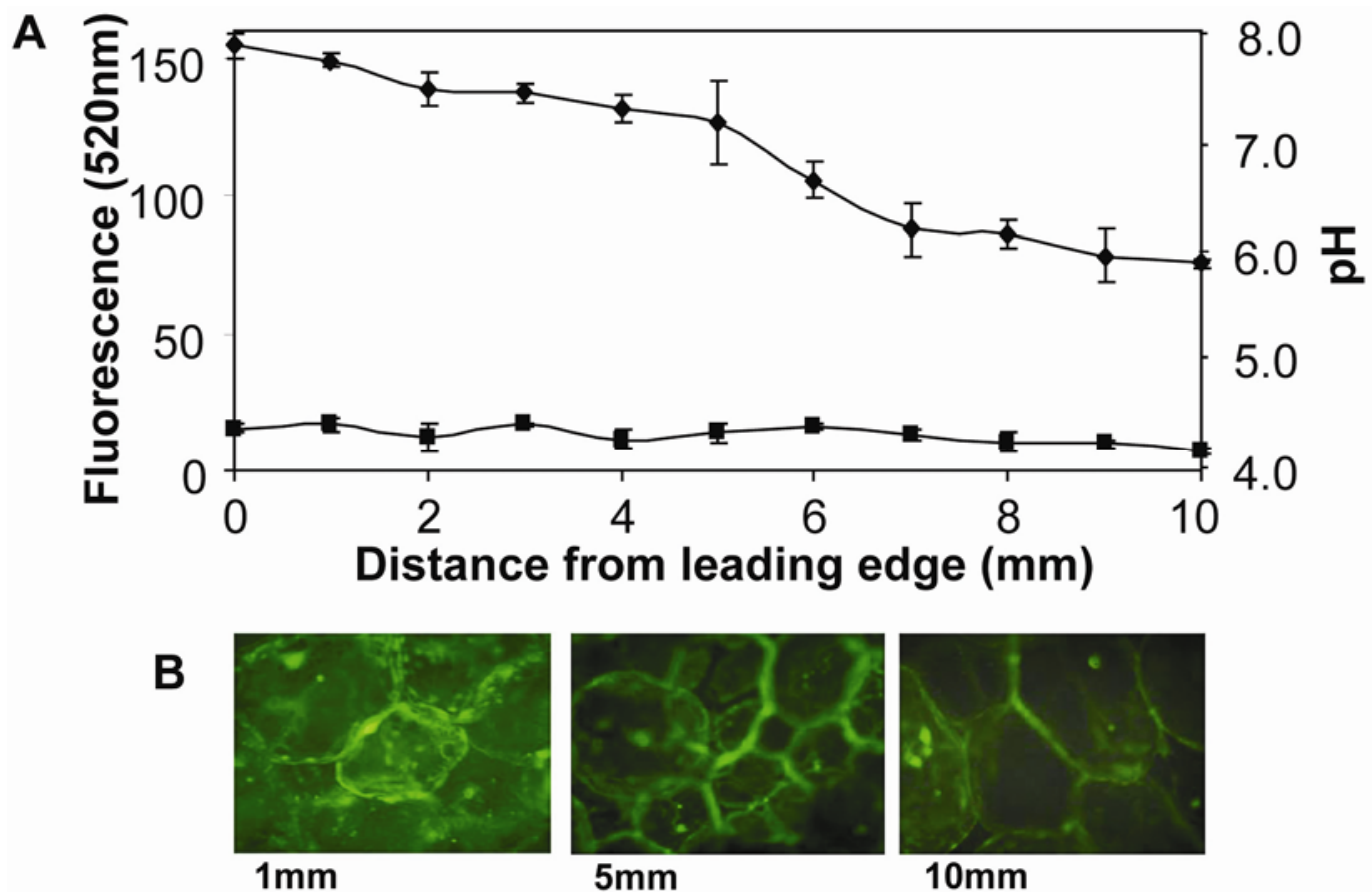

Fig. 1. Measurement of the local $\mathrm{pH}$ environment in tomato fruit at the leading edge of the decay caused by Colletotrichum coccodes infection. A, pH values as a function of distance from the leading edge of the decay in infected $(\bullet)$ and uninfected ( $\boldsymbol{\square})$ tissue. B, Fluorescence micrograph with $2^{\prime}, 7^{\prime}-$ bis(carboxyethyl)-5(6)-carboxyfluorescein (BCECF) at different distances from the region of decay. The changes in pH were detected microscopically in strips of tissue, $10 \mathrm{~mm}$ long by $1 \mathrm{~mm}$ thick, stained by BCECF fluorescence dye after correlating fluorescent values with direct pH determinations obtained by a piercing $\mathrm{pH}$ electrode. Fluorescence was detected by Leica fluorescence binocular; the average value of 50 evaluated cells is reported. A representative picture of cells at 1,5 , and $10 \mathrm{~mm}$ for the hyphal front is presented in $\mathrm{B}$. 

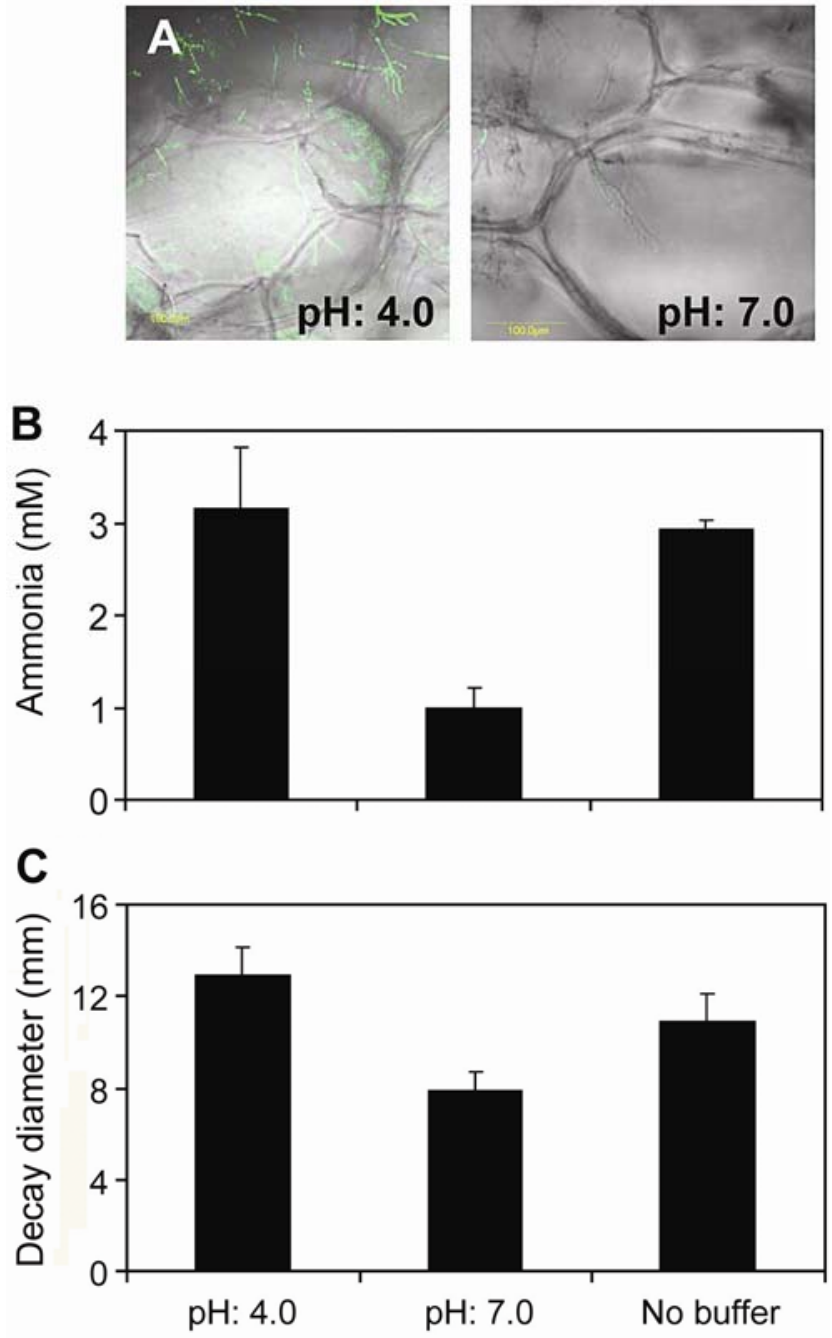

Fig. 2. Ammonia accumulation, $\mathrm{pH}$ measurement by $2^{\prime}, 7^{\prime}$ bis(carboxyethyl)-5(6)-carboxyfluorescein (BCECF) fluorescent dye, and pathogenicity of Colletotrichum coccodes on tomato fruit treated with and without $50 \mathrm{mM}$ phthalate buffer at $\mathrm{pH} 4.0$ and 7.0. The buffer $(50 \mu \mathrm{l})$ was applied twice a day to the infection site during $48 \mathrm{~h}$ after inoculation. A, BCECF fluorescence $(48 \mathrm{~h})$. B, Ammonia accumulation in the infection zone. C, Decay diameter of the infection zone. Average values of ammonia and decay development are the result of 20 independent inoculations. A representative picture of infected and BCECF-stained tomato cells detected by confocal microscope is presented. dependency on ammonia secretion by $C$. coccodes, nit ${ }^{-}$and are $^{-}$mutants of $C$. coccodes, which are impaired in ammonia secretion, were isolated in two independent ways: nit $^{-}$mutants by selection on potassium chlorate (Correll et al. 1987) and are $A^{-}$mutants by selection on hygromycin after gene disruption of a global nitrogen regulator AREA.

The resultant spontaneous mutants obtained on potassium chlorate were classified as $n i t 1^{-}$and $n i t 3^{-}$(putative lesion in nitrate and nitrite reductase) based on their selective growth on specific nitrogen sources (Table 1). Although wild-type (WT) C. coccodes grew on all media tested, nit $1^{-}$and nit $3^{-}$had a sparse appearance on nitrate. Growth on reduced nitrogen sources such as hypoxanthine, urea, and ammonia did not affect $n i t 1^{-}$and $n i t 3^{-}$; however, nit $3^{-}$could not grow on nitrite. Measurement of nitrate reductase activity in these mutants revealed that, although the WT strain showed a nitrate reductase activity of $5 \mu \mathrm{mol} / \mathrm{g}$ of $\mathrm{FW} / \mathrm{h}$, the $n i t 1^{-}$and $n i t 3^{-}$mutant strains showed no detectable activity (results not shown).

The are $^{-}$-type mutants were obtained by transformation of the WT strain with a construct in which the hygromycin phosphotransferase (hph) cassette was flanked on both sides by 748 and 746 bases of genomic AREA homolog (National Center for Biotechnology Information [NCBI] accession number EU170506). Hygromycin-resistant transformants were subjected to a second round of screening on $\mathrm{KNO}_{3}$, resulting in the detection of 50 mutants. The insertion was verified by polymerase chain reaction (PCR) using specific primers matching the $C$. coccodes AREA gene and the hygromycin resistance gene, and the expected 648- and 657-bp amplicons were obtained (results not shown). In addition, Southern hybridization to $C l a \mathrm{I} / X h o \mathrm{I}$ double digests and probed with the $A R E A$ gene revealed the expected fragments of 833 and $412 \mathrm{bp}$ for the WT and mutant strain, respectively (Fig. 4B). The ectopic $_{801}$ strain also showed both the 833- and 412-bp frag-

Table. 1. Media requirements of $n i t^{-}$and $a r e A^{-}$mutants, showing growth of Colletotrichum coccodes isolates on different nitrogen sources ${ }^{\mathrm{a}}$

\begin{tabular}{lccccc}
\hline Isolate & Nitrate & Nitrite & Hypoxanthine & Urea & Ammonia \\
\hline WT & + & + & + & + & + \\
nit1 & - & + & + & + & + \\
nit3 $^{-}$ & - & - & + & + & + \\
areA $^{-}$ & - & - & - & \pm & + \\
\hline
\end{tabular}

${ }^{\text {a }}$ Four isolates of $C$. coccodes - the wild type (WT) and nit $1^{-}$, nit $3^{-}$, and are $A^{-}$mutants-were grown on minimal solid medium containing nitrate, nitrite, hypoxanthine, urea, or ammonia; $-=$ sparse growth and $+=$ full growth.
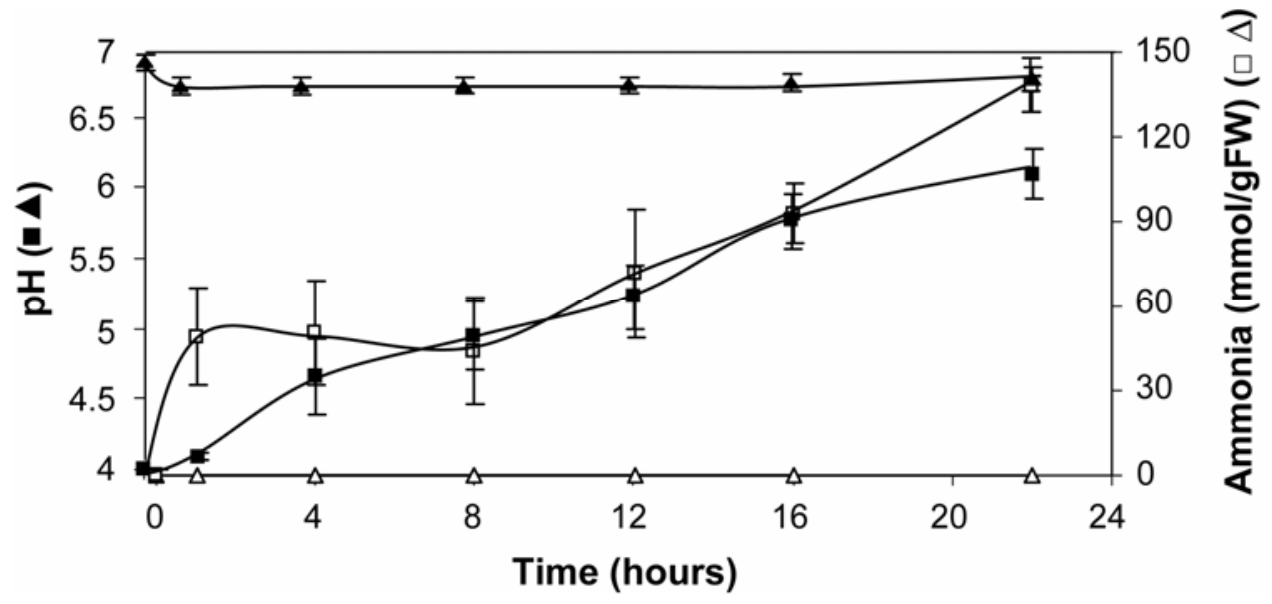

Fig. 3. Effect of initial pH on ammonia secretion. Spores of Colletotrichum coccodes were inoculated into Mathur's media (pH 5.2) and, 3 days later, the fungal mat was transferred to secondary media (see Materials and Methods) at initial $\mathrm{pH} 7.0$ or 4.0. The changes in $\mathrm{pH}$ (initial $\mathrm{pH} 7.0, \mathbf{\Delta}$; initial $\mathrm{pH} 4.0$, $\mathbf{\square}$ ) and ammonia (initial $\mathrm{pH} 7.0, \Delta$; initial $\mathrm{pH} 4.0, \square$ ) were followed for $22 \mathrm{~h}$. 
ments. Relative expression analysis of $A R E A$ by quantitative PCR showed abrogation of AREA expression in the three independent are $^{-}$mutants compared with the WT and ectopic ${ }_{801}$ strains (Fig. 4C). The are $A^{-}$mutant displayed sparse growth on all nitrogen sources except ammonia (Table 1) and 10-fold reduced activity of nitrate reductase compared with the WT strain. These results are consistent with other $\operatorname{are}^{-}$mutants from different fungi (Correll et al. 1987).

\section{Characterization of nit $^{-}$and are $^{-}$mutants.}

The WT and mutant strains were further examined for their effect on ammonia accumulation. When the WT strain was grown at $\mathrm{pH} 4.0$ (buffered conditions) in the presence of $\mathrm{KNO}_{3}$ as the sole nitrogen source, the amount of ammonia that accumulated inside and outside the hyphae (secreted to the media) was 85 and $55 \mathrm{mmol} / \mathrm{g}$ of FW, respectively (Fig. 5A). However, if the same strain was grown at $\mathrm{pH} 7.0$, the ammonia accumulated inside the hyphae amounted to $38 \mathrm{mmol} / \mathrm{g}$ of $\mathrm{FW}$ and the amount secreted to the media was only $5 \mathrm{mmol} / \mathrm{g}$ of FW (Fig. 5A). The results corroborate the $\mathrm{pH}$ dependency of ammonia induction and show that BCECF fluorescence correlates with internal ammonia accumulation inside the hyphae (Fig. 5B). Analysis of ammonia accumulation in the nit $1^{-}$and nit $3^{-}$mutant when subcultured in secondary media in the presence of $\mathrm{KNO}_{3}$ at $\mathrm{pH} 4.0$ showed approximately 2.5- and 10fold less ammonia production inside the hyphae and secreted to the media, respectively, relative to the WT strain. However, no significant differences between the WT, nit $1^{-}$, and nit $3^{-}$ strains were detected when grown in the secondary $\mathrm{pH} 7.0$ media for $24 \mathrm{~h}$ (Fig. 5). It is likely that, at high $\mathrm{pH}$, the fungi have residual internal sources of reduced nitrogen that enable them to produce a reduced amount of ammonia. When all the
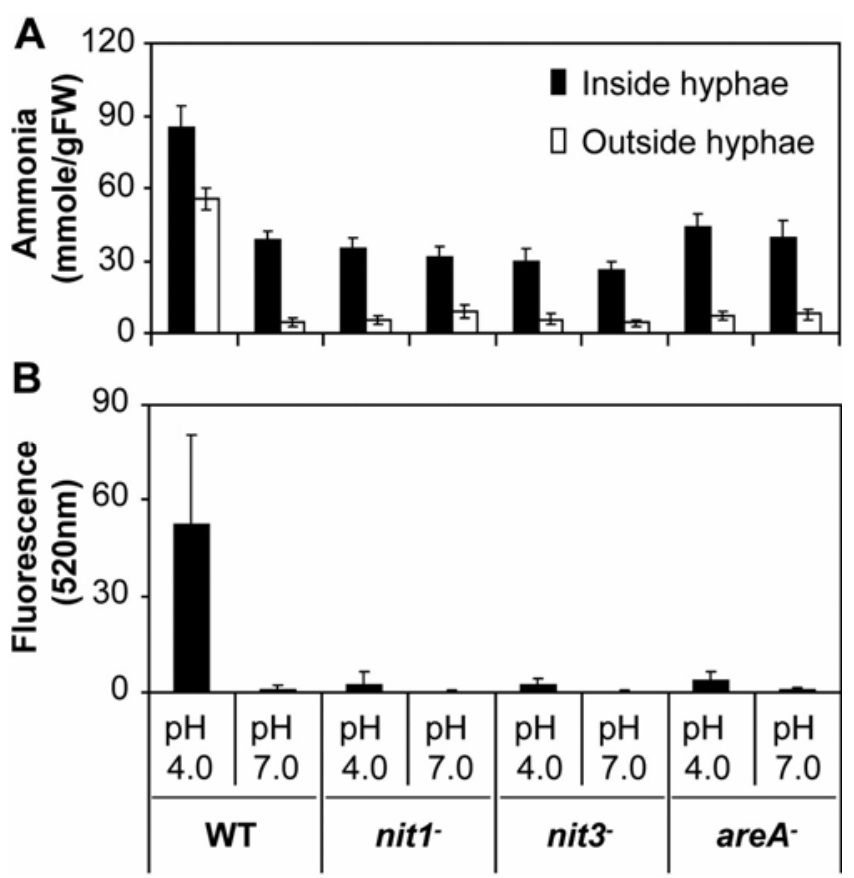

Fig. 5. Effects of $\mathrm{pH}$ on ammonia accumulation in Colletotrichum coccodes wild-type (WT) and mutants strains. Spores of $C$. coccodes or $C$. coccodes nit $1^{-}$, nit $3^{-}$, and are $A^{-}$mutants were inoculated into primary Mathur's media, and 3 days later, the fungal mat was transferred to secondary media buffered to $\mathrm{pH} 7.0$ or 4.0 in the presence of $\mathrm{KNO}_{3}$. A, Ammonia accumulation in the hyphae and culture media after $24 \mathrm{~h}$ of fungal growth and $\mathbf{B}, 2^{\prime}, 7^{\prime}$-bis(carboxyethyl)-5(6)-carboxyfluorescein fluorescence of the hyphae in the corresponding treatments analyzed by Sigma Scan software using confocal microscope.
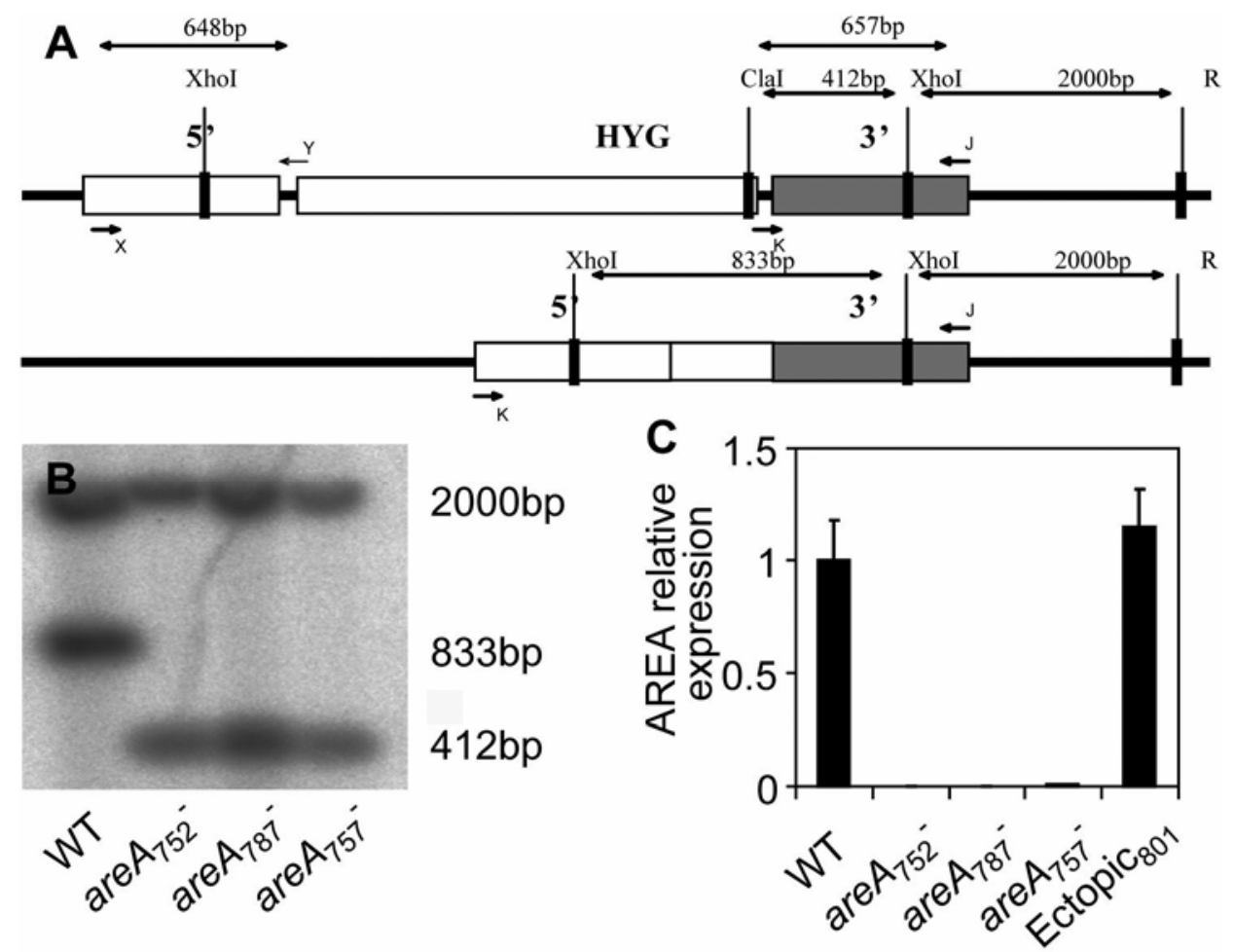

Fig. 4. Detection of $a r e A^{-}$insertion and ectopic mutants. A, Schematic illustration of $a r e A^{-}$ortholog mutagenesis by hygromycin insertion; the different fragments, primers, and restriction-site positions of XhoI and ClaI are shown. Top: predicted genomic structure of hygromycin insertion line. Bottom: predicted wild-type (WT) genomic structure. The genomic sequence (rectangle colored in gray) represent the probe that was used for Southern analysis and R represents a predicted XhoI or ClaI site. B, Southern analysis of $\mathrm{ClaI} / \mathrm{XhoI}$ double digest. C, Relative AreA gene expression detected by quantitative real-time polymerase chain reaction $24 \mathrm{~h}$ after transfer of the growing hyphae from the primary medium to the secondary medium. The relative expression values normalized against tubulin expression are the averages \pm standard deviations of three replications of the treatment. Analysis was carried out for the three independent are $A^{-}$mutants and ectopic and WT lines. 
are $A^{-}$mutant lines were grown on nitrate, they produced and secreted reduced amounts of ammonia similar to the nit ${ }^{-}$strains (results of one representative line are presented in Figure 5A). The ectopic ${ }_{801}$ strain showed behavior similar to WT strain, with values of ammonia accumulation inside and outside the hyphae of 66 and $44 \mathrm{mmol} / \mathrm{g}$ of FW, respectively. However, if the same strain was grown at $\mathrm{pH} 7.0$, the ammonia accumulated inside the hyphae amounted to $31 \mathrm{mmol} / \mathrm{g}$ of $\mathrm{FW}$ and the amount secreted to the media was only $6 \mathrm{mmol} / \mathrm{g}$ of FW.

\section{Pathogenicity of nit $^{-}$and are $A^{-}$mutants.}

WT and mutant strains were compared for virulence by hyphal mat inoculation on fruit. After 2 days of growth, the ammonia concentration and $\mathrm{pH}$ level in fruit inoculated with the WT strains was $1.0 \mathrm{mM}$ and 7.7 , respectively, whereas, in the fruit inoculated with the nit $1^{-}$and nit $3^{-}$mutants, the concentration of ammonia ranged between 0.3 and $0.5 \mathrm{mM}$ and the $\mathrm{pH}$ between 6.7 and 6.5 (Fig. 6A and B). Significantly, the mutant nit $1^{-}$and $n i t 3^{-}$lines showed a reduced infection rate (Fig. 6C). The changes in ammonia, $\mathrm{pH}$, and infection rate between WT and nit $^{-}$mutants could be complemented by the addition of glutamine and ammonia but not nitrate (Fig. 6). These results
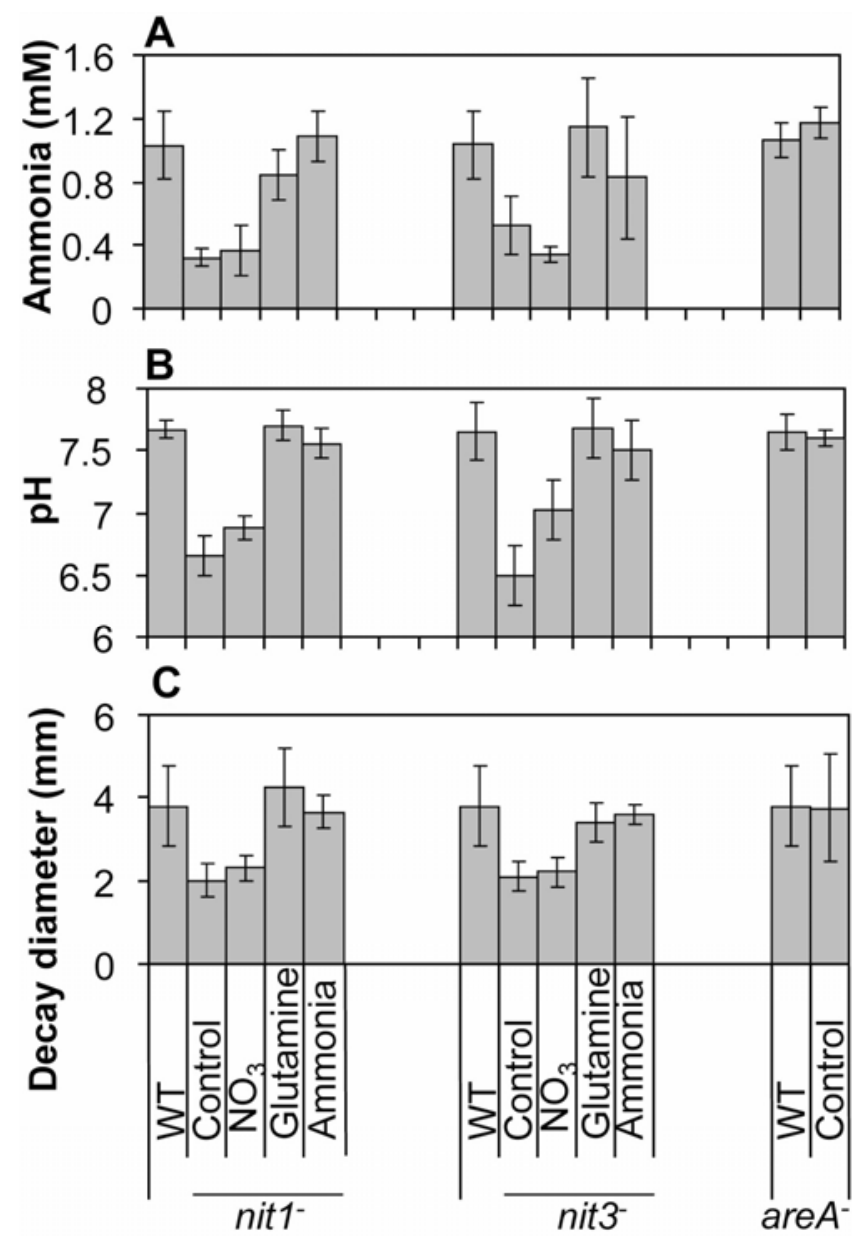

Fig. 6. Ammonia accumulation, $\mathrm{pH}$ changes, and decay diameter of wildtype (WT), nit $1^{-}$, nit $3^{-}$, and are $A^{-}$strains of Colletotrichum coccodes and their complementation by supplemental amino acids. Spores of $C$. coccodes strains were inoculated into primary Mathur's media and, 3 days later, the fungal mat was transferred to secondary media containing $\mathrm{KNO}_{3}$; the resultant mat was used for inoculation of tomato mesocarp. Ammonia, $\mathrm{pH}$, and decay diameter were measured on the fruit $48 \mathrm{~h}$ later. Complementation was carried out by application of $10 \mathrm{mM} \mathrm{NO}_{3}$, glutamine, or ammonia twice a day $(50 \mu \mathrm{l})$ to the infection zone. A, Ammonia accumulation; B, $\mathrm{pH}$; and $\mathbf{C}$, decay diameter. showed that mutants that are compromised with respect to ammonia assimilation have a reduced level of virulence.

When infections of tomato fruit were carried out by hyphal mat inoculation and evaluated after $48 \mathrm{~h}$, no difference between WT and are $^{-}$mutants was obtained (Fig. 6). Comparison to the ectopic ${ }_{801}$ strain did not result in differences either (results not shown). Because this test likely created conditions of the later phase of the interaction, we also examined infection by subepidermal spore inoculation to obtain the earlier biotrophic interaction (discussed below). In this case, the mutant lines showed a 10-fold reduction in ammonia accumulation and a reduction of $1.5 \mathrm{pH}$ units at the infection site 7 days later. Importantly, the infection rate of the mutant lines as measured by anthracnose diameter was significantly delayed compared with

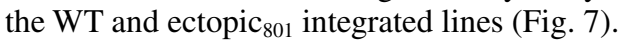

\section{DISCUSSION}

\section{Ammonia as a factor mediating} environmental alkalinization.

Previous studies have suggested that alkalinization of decaying tissue by Colletotrichum spp. is related to the accumulation of ammonia. It was hypothesized that alkalinization serves as a factor for the modulation of pathogenicity (Eshel et al. 2002; Prusky et al. 2001). In the present work, we examined the accumulation of ammonia in developing hyphae of $C$. coccodes and followed fruit tissue $\mathrm{pH}$ by macroscopic and microscopic means. Whereas the $\mathrm{pH}$ of the healthy tomato tissue showed a value of 4.2 , the $\mathrm{pH}$ in the infected tissue reached up to 7.9. The steep $\mathrm{pH}$ gradient implies that the buffering capacity of
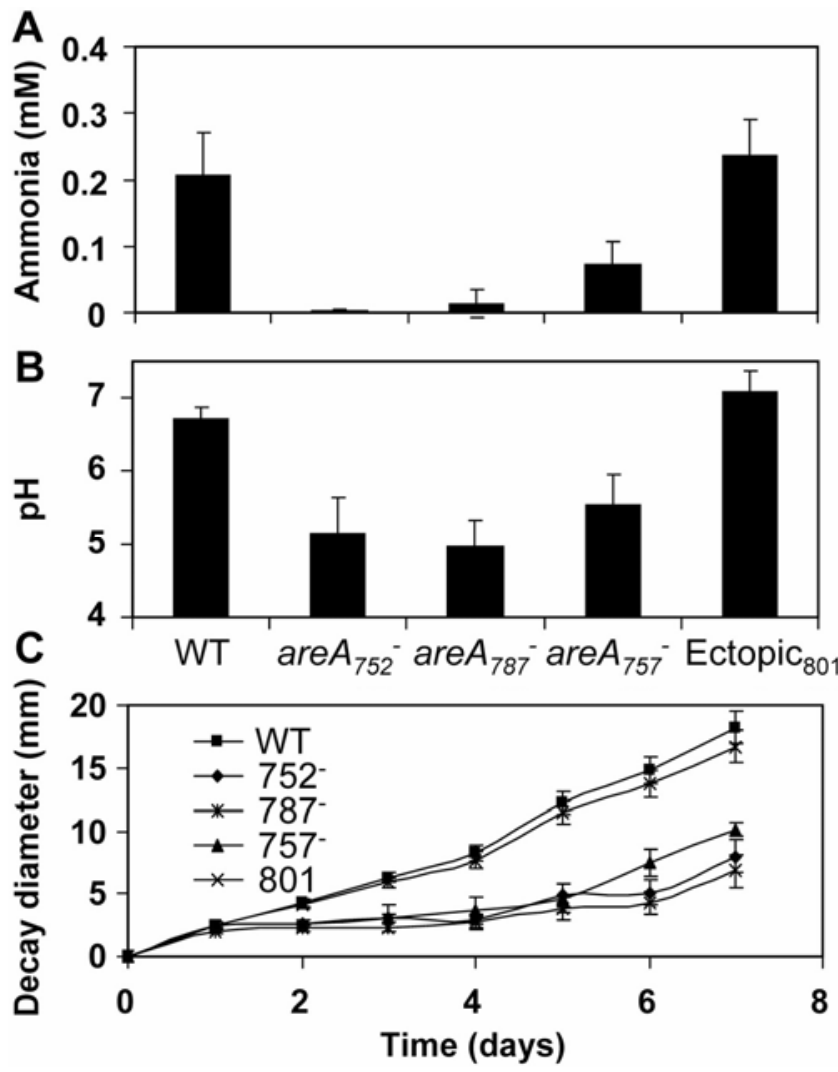

Fig. 7. Ammonia accumulation, $\mathrm{pH}$ changes, and decay diameter of are $A^{-}$ ${ }_{752}$, are $A^{-}{ }_{787}$, and are $A^{-}{ }_{757}$, mutants of Colletotrichum coccodes compared with the wild-type (WT) strain and untargeted strain ectopic ${ }_{801}$. Infection was initiated by injecting spores of the specified $C$. coccodes strain into the mesocarp. After 72 h, A, ammonia and B, pH were measured. C, Decay diameter was measured for 7 days. 
the fruit is actively challenged by continuous alkalinization processes at the infection site. Ammonia was detected in the hyphae and this correlated with hyphal $\mathrm{pH}$ measurements both in vitro and in situ. The results support the hypothesis that the release of ammonia from the fungal hyphae is a major factor driving the local elevation in $\mathrm{pH}$. This ammonification process has been observed in $C$. gloeosporioides and Alternaria alternata attacking a wide variety of fruit, suggesting a commonality in the colonization process that requires modulation of environmental $\mathrm{pH}$ by postharvest pathogens (Prusky and Yakoby 2003).

Tissue alkalinization and success of infection processes, such as secretion of pathogenicity factors, have been shown to be related (Drori et al. 2003; Kramer-Haimovich et al. 2006; Yakoby et al. 2000). Kramer-Haimovich and associates (2006) suggested that ammonia directly activates the expression of pathogenicity factors such as $P E L B$ encoding for pectate lyase in $C$. gloeosporioides. To examine the importance of ammonia accumulation in the colonization of $C$. coccodes in tomato, we modulated ammonia accumulation by exogenic treatments with buffer solutions, and developed nit $^{-}$and are $^{-}$, the reducedammonia-producing mutants.

Exposure of growing hyphae to $\mathrm{pH} 4.0$ significantly increased the total level of ammonia accumulation in vitro and in situ. However, exposure to $\mathrm{pH} 7.0$ had no effect, showing the importance of low $\mathrm{pH}$ in the control of active fungal processes. Note that $\mathrm{pH} 4.0$ approximates the natural $\mathrm{pH}$ encountered by the fungus in this environment as it is released from the quiescent phase (Prusky 1996). Hence, conditions of external $\mathrm{pH}$ are utilized by the fungus to regulate ammonia production. Importantly, ammonia accumulation was always accompanied by increased decay development in the fruit. Although it has been suggested that prior changes in fruit $\mathrm{pH}$ are important for release of the pathogen from the quiescent state (Yakoby et al. 2000), our results do not support this model. On the contrary, our results suggest that low fruit $\mathrm{pH}$ stimulates the fungi to reach an effective virulent state. Note that other changes occurring naturally in ripening fruit, such as shift in carbon and nitrogen sources and availability or decline in antifungal materials (Miyara et al. 2008; Yakoby et al. 2000), may also be responsible for release of the pathogen from the quiescent state.

Our results further show that ammonia secretion is severely compromised in nit $^{-}$and are $A^{-}$mutants. These mutants likely show decreased ammonia production due to impaired utilization of external nonreduced nitrogen sources (Marzluf 1997). Although some capacity for ammonia secretion remains, this is likely the result of residual internal sources of reduced nitrogen. Interestingly, although nitrogen reductase activity was abrogated in the nit $^{-}$mutants, residual activity was still present in the are $^{-}$mutants, illustrating that nitrogen utilization is only partially blocked in those mutants. Indeed, while nit $^{-}$mutant lines showed a reduced pathogenicity rate using hyphal mat inoculation, the are $^{-}$mutants showed reduced pathogenicity only by infection through spore injection. This behavior may support the importance of $A R E A$ in the transformation from biotrophic to necrotrophic conditions. Pellier and associates (2003) recently indicated that elimination of AREA homolog of the hemibiotroph $C$. lindemuthianum did not affect fungal growth as a biotroph during the initial phases of host colonization but the pathogen was unable to make the usual switch to necrotrophic growth. In our case, the are $^{-}$mutants could develop in necrotrophic conditions (wound inoculation by the hyphal mat inoculation method) but showed delayed development when spores were induced to go through the late stages of a biotrophic interaction (spore injection method). This suggests that, during some periods, the fungus needs to take advantage of less-favored nitrogen sources regulated by AREA.
These findings point to a direct, albeit nonlinear, connection between the amount of ammonia produced by the fungus and its pathogenicity. One explanation for the increased virulence with ammonia may be the direct activation of gene expression (Kramer-Haimovich et al. 2006). Alternatively, ammonia might be directly toxic to the host cell's metabolism. For example, tomato, like many other hosts, is sensitive to ammonia toxicity and shows delayed growth when supplemented with 0.1 to $10 \mathrm{mM}$ ammonia (Feng and Barker 1992). Our results show that, at the $C$. coccodes infection site, up to $4 \mathrm{mM}$ ammonia can be detected, a result that is well within the cytotoxic range.

The common model system for pathogenicity activation by ammonia suggests that ammonia secreted by the pathogen alkalinizes its immediate environment: this alkalinization represents the basic signal for activation of the $\mathrm{pH}$-dependent transcriptional regulator $\mathrm{PacC}$, which modulates the activation of virulence factors such as PEL (Drori et al. 2003; Miyara et al. 2007, 2008; Prusky et al. 2001; Yakoby et al. 2001). This work shows that the ammonia, in and of itself, elevates the virulence of $C$. coccodes even when the $\mathrm{pH}$ of the environment is maintained acidic.

Our results support the following scenario in which both ambient $\mathrm{pH}$ and nitrogen availability are major regulators of $C$. coccodes ammonification. The accumulation of amino acids during fruit ripening (Boggio et al. 2000) could contribute to substrate availability to the pathogen, thereby ensuring ammonia production and initiating a shift from the biotrophic-quiescent to the necrotrophic-colonizing stage. The presence of alkaline conditions inside the hyphae in symptomless tissue suggests that ammonia production inside the hyphae probably begins during the biotrophic stage, and the release of ammonia to the host environment results in activation of the necrotrophic stage. The ability of the pathogen to accumulate large amounts of ammonia in decaying tissue further ensures the elevation in $\mathrm{pH}$ and virulence. Altering ammonia secretion and $\mathrm{pH}-\mathrm{regu}-$ lated processes could form the basis for a viable strategy to delay, reduce, or even prevent disease development by this plantpathogenic fungus.

\section{MATERIALS AND METHODS}

Fungal isolate, media, and growth conditions.

Single-spore cultures of $C$. coccodes isolate $C c$-138 (supplied by L. Tzror) were obtained from decayed potato (Solanum tuberosum) tubers in Israel (Nitzan et al. 2002) and shown to be pathogenic on tomato fruit. C. coccodes was routinely cultured on Mathur's media containing chloramphenicol at 250 $\mathrm{mg} / \mathrm{liter}$. The fungus was also grown in $40 \mathrm{ml}$ of liquid Mathur's medium (Tu 1985) at $\mathrm{pH}$ 5.0, inoculated to a density of $1 \times 10^{6}$ spores/flask. Mathur's medium $\left(\mathrm{M}_{3} \mathrm{~S}\right)$ contains the following reagents (per liter): $2.5 \mathrm{~g}$ of $\mathrm{MgSO}_{4} \cdot 7 \mathrm{H}_{2} \mathrm{O}, 2.7 \mathrm{~g}$ of $\mathrm{KH}_{2} \mathrm{PO}_{4}, 1.0 \mathrm{~g}$ of Bacto peptone, $1.0 \mathrm{~g}$ of Bacto yeast extract (Difco Laboratories, Detroit), $10 \mathrm{~g}$ of sucrose, and $250 \mathrm{mg}$ of chloramphenicol (primary medium). Cultures were incubated in a $24^{\circ} \mathrm{C}$ incubator with shaking at $150 \mathrm{rpm}$ for 3 days and were harvested by filtration through a sterile Büchner funnelfitted filter paper. The hyphal mat was washed twice by filtering $40 \mathrm{ml}$ of sterile distilled water through it. The washed mycelia were resuspended in $40 \mathrm{ml}$ of fresh medium containing the following reagents (per liter): $4 \mathrm{~g}$ of $\mathrm{K}_{2} \mathrm{HPO}_{4}, 2 \mathrm{~g}$ of $\mathrm{MgSO}_{4} \cdot 7 \mathrm{H}_{2} \mathrm{O}, 5 \mathrm{~g}$ of $\mathrm{KNO}_{3}, 0.3 \mathrm{~g}$ of $\mathrm{CaCl}_{2} \cdot 2 \mathrm{H}_{2} \mathrm{O}, 10 \mathrm{mg}$ of $\mathrm{FeCl}_{3}$, and $10 \mathrm{~g}$ of glucose as the carbon source (secondary medium). The medium was buffered with $50 \mathrm{mM}$ phthalatehydroxide buffer (Sigma-Aldrich, St. Louis) to obtain $\mathrm{pH}$ values of 4.0 and 7.0. The initial $\mathrm{pH}$ in each flask was determined after the medium had been autoclaved but prior to inoculation. 
The experiments were repeated at least three times, and the results of a single representative experiment are shown here.

\section{Fruit inoculation, fruit treatments, and infection parameters.}

For inoculation with fungal hyphae, freshly harvested mature, color-break tomato fruit of the same age and size (Lycopersicon esculentum cv. Hazera 1402, susceptible to C. coccodes) from a greenhouse in Yaziz, Israel, were used for inoculations. Fruit inoculation was carried out on the mesocarp. A 1-mmthick, 10-mm-diameter section of the peel pericarp tissue was removed from the fruit and replaced by a 1-mm-thick hyphal disk of $C$. coccodes mycelia ("hyphal mat infection method"). This hyphal disk was obtained after growing spores for 3 days on primary media and 1 day on secondary media. Following inoculation, fruit were incubated at $22^{\circ} \mathrm{C}$ and $95 \%$ relative humidity in covered plastic containers containing wet paper towels. The diameter of decay development was measured $48 \mathrm{~h}$ after inoculation and reported in millimeters over the $10-\mathrm{mm}$ diameter of infection with the hyphae mat. The resulting decay development of four inoculations per fruit on five different fruit (20 inoculation replicates) per treatment are reported. In some experiments, the inoculation sites were exogenously treated by pipetting $50 \mu \mathrm{l}$ of phthalate, $\mathrm{pH} 4.0$ or $\mathrm{pH} 7.0$, or 10 $\mathrm{mN} \mathrm{KNO}_{3}$, glutamine, or ammonia.

For inoculation with spores ("spore injection method"), $5 \mu \mathrm{l}$ of a conidial suspension $\left(10^{6}\right.$ conidia/ml $)$ was injected $(1 \mathrm{~mm}$ deep) into five horizontally spaced inoculation spots on each of five different fruits per treatment (i.e., 25 inoculation replicates per treatment). Experiments were repeated at least three times, with the results of a single representative experiment shown.

\section{pH measurement and ammonia detection.}

Ammonia and $\mathrm{pH}$ were measured in $0.5-\mathrm{ml}$ aliquots sampled at various times after fungal inoculation from fruit tissue after homogenization and centrifugation and from dried fungal tissue after homogenization in water. Pericarp $\mathrm{pH}$ was determined by making an approximately $0.2-\mathrm{mm}$-deep cut with a scalpel blade and applying a Termo-Orion Model 9810BN microcombination $\mathrm{pH}$ electrode (Thermo Fisher Scientific, Inc., Waltham, MA, U.S.A.) directly against the exposed tissue. Ammonia was detected by colorimetric reaction with an ammonium test kit (Merck, Darmstadt, Germany). Ammonia concentrations in infections were reported in millimolar and those in in vitro experiments were reported as mmol per gram FW. All experiments consisted of three replicates and were repeated at least twice. The results of one representative experiment are presented with standard error of the means.

\section{Generation and characterization of nit $^{-}$mutants.}

The nit $^{-}$mutants were generated in the presence of potassium chlorate (Puhalla 1985). We carried out partial phenotyping of nit ${ }^{-}$mutants (nit $1^{-}$versus nit $3^{-}$) by placing mycelial plugs of each $n i t^{-}$mutant on minimal medium amended with hypoxanthine at $0.2 \mathrm{~g} / \mathrm{liter}$, ammonia at $1 \mathrm{~g} / \mathrm{liter}$, urea at 2 $\mathrm{g} / \mathrm{liter}$, and $\mathrm{NaNO}_{2}$ at $0.5 \mathrm{~g} /$ liter or $\mathrm{NaNO}_{3}$ at $2 \mathrm{~g} / \mathrm{liter}$ (Korolev et al. 2000). Plates were incubated for 5 days at $27^{\circ} \mathrm{C}$ in the dark. Classification as different $n i t^{-}$mutants considered the growth phenotype on all media (Puhalla 1985).

\section{Fluorescence staining.}

Changes in $\mathrm{pH}$ of the tissue and inside the infecting hyphae were detected using the fluorescent probe BCECF. Staining for $\mathrm{pH}$ evaluation in the infected tissue, the infecting hyphae, and the growing hyphae in vitro was done by exposing the tissue to $10 \mu \mathrm{M}$ of the fluorescent probe BCECF (Molecular Probes,
Leiden, The Netherlands) for 15 min in the dark at $24^{\circ} \mathrm{C}$ and terminated by rinsing the sample several times in phosphatebuffered saline. Sampling of the infected tissue for $\mathrm{pH}$ evaluation was done by slicing parenchyma fruit strips $(1 \mathrm{~mm}$ thick and $20 \mathrm{~mm}$ long) of the tomato pericarp and mesocarp tissue, starting at the infected point. The evaluation of $\mathrm{pH}$ based on the fluorescence of the tissue was done by parallel measurement of the fluorescence values versus the actual $\mathrm{pH}$ determined by a piercing $2 \mathrm{~mm}-\mathrm{pH}$ electrode probe (Termo-Orion Model 9810BN microcombination pH electrode; Thermo Fisher Scientific, Inc.). The calibration of the $\mathrm{pH}$ values was done by adding $0.1 \mathrm{M}$ external $\mathrm{pH}$ phosphate buffer at a $\mathrm{pH}$ range from 4.0 to 7.0. The relation between the fluorescence value and the actual $\mathrm{pH}$ was obtained after 50 independent-buffer applications to the tissue for each particular $\mathrm{pH}$ value. In the infected tissue, the average of five independent fluorescent values of parenchyma cells at each millimeter of the 10-mm-long strip was considered as a single replicate of the experiment. Ten different strips were analyzed and reported using SigmaScan software. As control for the $\mathrm{pH}$ changes at different distances from the infected point, a similar strip was used from the opposite, noninfected side of the same fruit that showed a constant $\mathrm{pH}$ of 4.2. Wounded uninfected tissue did not show any $\mathrm{pH}$ change. The strips were viewed with a Leica fluorescence binocular. Intracellular fluorescence was excited at $488 \mathrm{~nm}$ and emission was detected at $520 \mathrm{~nm}$.

Differential $\mathrm{pH}$ of the hyphae viewed with a confocal microscope using the BCECF staining was denoted by the brightness of internal mycelia tissue. Bright hyphae, mostly resulting from bright vacuoles, showed an approximate $\mathrm{pH}$ of 6.0 in double-distilled water, whereas hyphae without brightness showed an approximate $\mathrm{pH}$ of 5.0. Intracellular fluorescence was excited at $488 \mathrm{~nm}$ and emission was detected at $520 \mathrm{~nm}$ using a Laser Scanning confocal Microscope Olympus IX81. Twenty representative evaluations of the stained hyphae were observed and one of them presented in the text. The pictures were analyzed by SigmaScan software to obtain average fluorescence for each cell. Each experiment was repeated at least four times and one single representative experiment is reported.

\section{Vector construction.}

The sequence of AREA homolog of $C$. coccodes was obtained using primers CCT GAA CTT GCG CAA GAA GCG GCT AC (forward) and GTG CTG TAC TGG CCA GGA AG (reverse) based on Pellier and associates (2003) (NCBI accession number EU170506). The deletion of AREA ortholog from 1,079 bp upstream to $1,351 \mathrm{bp}$ (position 657 to position 929) was created, using hygromycin $\mathrm{B}$ under control of the TRPC promoter from plasmid pGEM:hyg (Horowitz et al. 2006) as a selectable marker. The hygromycin marker was flanked by an upstream sequence $(1,351$ to $2,018 \mathrm{bp})$ and a downstream sequence (422 to $1,079 \mathrm{bp}$ ) of the AREA gene. The construct was assembled using the Multi-Site Gateway Three-Fragment Vector Construction Kit (Invitrogen, Carlsbad, CA, U.S.A.). The products of the AREA PCR were gel purified using a Qiaquick kit (Qiagen, Hilden, Germany) and cloned into plasmids (pDONR.P4-P1R, pDONR.221, and pDONR.P2R-P3) using standard $\mathrm{Bp}$ clonase 2 reaction (Invitrogen). The insert of the hygromycin entry clone was verified by sequencing. The plasmid was mixed with pDBEST R4-R3 and LR clonase plus to create Gene blast AREA. The created construct was designed to replace $A R E A$ from +422 to $+2,018$ bp. Full details of the development of this method are described elsewhere (Shafran et al. 2008). The construct was transformed into $C$. coccodes by electroporation (Yakoby et al. 2001). Transformants were grown as single colonies on hygromycin and then regrown on $\mathrm{KNO}_{3}$-containing media. DNA was extracted with the Master 
Pure Yeast Purification Kit (Epicentre Biotechnologies, Madison, WI, U.S.A.). Out of 140 transformants, 50 colonies were found to be positive by PCR and were identified as positive for are $A^{-}$deletion. DNA was extracted from three colonies of these deletion candidates. Southern analyses of these colonies revealed the deletion of $A R E A$, which was then confirmed by sequencing of the AREA deletion in the genome (Shafran et al. 2008).

\section{DNA manipulation.}

For genomic DNA extraction, fungi were grown in liquid $\mathrm{M}_{3} \mathrm{~S}$ for 3 days at $28^{\circ} \mathrm{C}$. For PCR analysis, $50 \mathrm{mg}$ of wet tissue was used, following the Master Pure Kit protocol (Epicentre Biotechnologies). For Southern analysis, genomic DNA was prepared (Moller et al. 1992) using $0.5 \mathrm{~g}$ of tissue.

Southern probe labeling and hybridization were performed according to previously published methods (Ausubel et al. 1991): $20 \mu \mathrm{g}$ of genomic DNA were cut with restriction enzymes XhoI and CalI. The probe was PCR fragmented from genomic DNA using primers TCT TGT ACA AAG TGG CGG AAC TGC ACG AGT ATT CA (forward) and CTG ACT CGG ATG AGG AGG ATG CGG CCG CCA (reverse).

PCR was performed at $58^{\circ} \mathrm{C}$ for 40 cycles by using primers for the $5^{\prime}$ end of the areA gene: areA5F TTG GCG GCC GCA GAA CGG ACC TGG CT and Hyg5R GCC TGG ACG ACT AAA CCA AA, and primers for the $3^{\prime}$ prime areA gene: Hyg3F CTG GAT CCA TCT CCT TGC AT and areA3R GAT ACA CAC ACC CGA TAT CGT GCAAG.

\section{RNA extraction and real-time PCR analysis.}

RNAs were extracted from $80 \mathrm{mg}$ (dry weight) of mycelium with an RNeasy Plant mini kit (QIAGEN Sciences, Hilden, Germany) and further purified by treatment with TURBO DNA free (Ambion, Austin, TX, U.S.A.). The reverse transcription reaction was performed on $10 \mu \mathrm{g}$ of total RNA with the Reverse-it first-strand synthesis kit (ABgene, Surrey, U.K.). Samples of cDNA were diluted 1:10 to the final template concentration for real-time PCR. Real-time PCR was performed with the RotorGene 3000 system (Corbett Research, Sydney, Australia). PCR amplification was performed with $3.4 \mu \mathrm{l}$ of cDNA template in $10 \mu \mathrm{l}$ of a reaction mixture containing $5 \mu \mathrm{l}$ of Syber-Green amplification kit (ABgene) and $300 \mathrm{nM}$ primers. PCR was carried out by using the following cycling program: $15 \mathrm{~min}$ at $94^{\circ} \mathrm{C}$, followed by 40 cycles of $94^{\circ} \mathrm{C}$ for $10 \mathrm{~s}, 60^{\circ} \mathrm{C}$ for $15 \mathrm{~s}$, and $72^{\circ} \mathrm{C}$ for $20 \mathrm{~s}$. The samples were subjected to melting curve analysis with the Rotor-Gene 6 software. All samples were normalized to Tubulin expression levels and values were expressed as the change in the increase or decrease of the relative levels of a calibrator sample. The forward and reverse primers for Tubulin were 5'-CCA TTG CTG TCG AGA G-3' and 5'-CCA GAC CGG CCA GTG C-3', respectively and for AREA were 5'-CGT GCA GTT CCG AGT C-3' and 5'-ACA GCA CCA CGA CAA CAA CG-3', respectively. Each experiment was repeated three times with similar results and results for one experiment are presented.

\section{ACKNOWLEDGMENTS}

This work was supported by the U.S.-Israel Binational Agricultural Research and Development Fund (research grant number IS-3945-06).

\section{LITERATURE CITED}

Arst, H. J., and Cove, D. 1973. Nitrogen metabolite repression in Aspergillus nidulans. Mol. Gen. Genet. 126:111-141.

Ausubel, F. M., Brent, R., Kingston, R. E., Moore, D. D., Seidman, J. G., Smith, J. A., and Struhl, K. 1991. Current Protocols in Molecular Biology. John Wiley and Sons, New York.
Boggio, S. B., Palatnik, J. F., Heldt, H. W., and Valle E. M. 2000 Changes in amino acid composition and nitrogen metabolizing enzymes in ripening fruits of Lycopersicon esculentum Mill. Plant Sci. 159:125133.

Coleman, M., Henricot, B., Arnau, J., and Oliver, R. P. 1997. Starvationinduced genes of the tomato pathogen Cladosporium fulvum are also induced during growth in planta. Mol. Plant-Microbe Interact. 10:11061109.

Correll, J. C., Klittich, C. J. R., and Leslie, J. F. 1987. Nitrate nonutilizing mutants of Fusarium oxysporum and their use in vegetative compatibility tests. Phytopathology 77:1640-1646.

Divon, H. H., Rothan-Denoyes, B., Davydov, O., Di Pietro, A., and Fluhr, R. 2005. Nitrogen-responsive genes are differentially regulated in planta during Fusarium oxysporum f. sp. lycopersici infection. Mol. Plant Pathol. 6:459-470.

Drori, N., Kramer-Haimovich, H., Rollins, J., Dinoor, A., Okon, Y., Pines, O., and Prusky, D. 2003. A combination of external $\mathrm{pH}$ and nitrogen assimilation affect secretion of the virulence factor pectate lyase by $C$. gloeosporioides. Appl. Environ. Microbiol. 69:3258-3262.

Eshel, D., Miyara, I., Ailing, T., Dinoor, A., and Prusky, D. 2002. pH regulates endoglucanase expression and virulence of Alternaria alternata in persimmon fruits. Mol. Plant-Microbe Interact. 15:774-779.

Feng, J., and Barker, A. V. 1992. Ethylene evolution and ammonium accumulation by nutrient-stressed tomato plants. J. Plant Nutr. 15:137-154.

Fu, Y. H., and Marzluf, G. A. 1990. nit-2, the major nitrogen regulatory gene of Neurospora crassa, encodes a protein with a putative zinc finger DNA-binding domain. Mol. Cell. Biol. 10:1056-1065.

Guaragnella, N., and Butow, R. A. 2003. ATO3 encoding a putative outward ammonium transporter is an RTG-independent retrograde responsive gene regulated by GCN4 and the Ssy1-Ptr3-Ssy5 amino acid sensor system. J. Biol. Chem. 278:45882-45887.

Horowitz, S., Freeman, S., Zveibil, A., and Yarden, O. 2006. A defect in nirl, a nirA-like transcription factor, confers morphological abnormalities and loss of pathogenicity in Colletotrichum acutatum. Mol. Plant Pathol. 7:341-354.

Korolev, N., Katan, J., and Katan, T. 2000. Vegetative compatibility groups of Verticillium dahlia in Israel: their distribution and association with pathogenicity. Phytopathology 90:529-536.

Kramer-Haimovich, H., Servi, E., Katan, T., Rollins, J., Okon, Y., and Prusky, D. 2006. Effect of ammonia production by Colletotrichum gloeosporioides on pelB activation, pectate lyase secretion, and fruit pathogenicity. Appl. Environ. Microbiol. 72:1034-1039.

Latunde-Dada, A. O. 2001. Colletotrichum: tales of forcible entry, stealth, transient confinement and breakout. Mol. Plant Pathol. 2:187-198.

Marzluf, G. A. 1997. Genetic regulation of nitrogen metabolism in the fungi. Microbiol. Mol. Biol. Rev. 61:17-32.

Miyara, I., Shafran, H.., Kramer Haimovich, H., Rollins, J., Sherman, A., and Prusky, D. 2008. Multifactor regulation of pectate lase secretion by Colletotrichum gloeosporioides pathogenic on avocado fruits. Mol. Plant Pathol. 9:281-291.

Moller, E. M., Bahnweg, G., Sandermann, H., and Geiger, H. H. 1992. A simple and efficient protocol for isolation of high molecular weight DNA from filamentous fungi, fruit bodies, and infected plant tissues. Nucleic Acids Res. 20:6115-6116.

Nitzan, N., Hazanovsky, M., Tal, M., and Tsror (Lahkim), L. 2002. Vegetative compatibility groups in Colletotrichum coccodes, the causal agent of black dot on potato. Phytopathology 92:827-832.

Pellier, A. L., Laugé, R., Veneault-Fourrey, C., and Langin, T. 2003. CLNR1, the AREA/NIT2-like global nitrogen regulator of the plant fungal pathogen Colletotrichum lindemuthianum is required for the infection cycle. Mol. Microbiol. 48:639-655.

Prusky, D. 1996. Pathogen quiescence in postharvest diseases. Annu. Rev. Phytopathol. 34:413-434

Prusky, D., and Yakoby, N. 2003. Pathogenic fungi: leading or led by ambient pH? Mol. Plant Pathol. 4:509-516.

Prusky, D., McEvoy, J. L., Leverentz, B., and Conway, W. S. 2001. Local modulation of host $\mathrm{pH}$ by Colletotrichum species as a mechanism to increase virulence. Mol. Plant-Microbe Interact. 14:1105-1113.

Puhalla, J. E. 1985. Classification of strains of Fusarium oxysporum on the basis of vegetative compatibility. Can. J. Bot. 63:179-183.

Shafran, H., Miyara, I., Eshed, R., Prusky, D., and Sherman, S. 2008. Development of new tools for studying gene function in fungi based on the Gateway system. Fungal Genet. Biol. Published online.

Snoeijers, S. S., Perez-Garcia, A., Joosten, M. H. A. J., and De Wit, P. J. G. M. 2000. The effect of nitrogen on disease development and gene expression in bacterial and fungal plant pathogens. Eur. J. Plant Pathol. 106:493-506.

Stephenson, S. A., Green, J. R., Manners, J. M., and Maclean, D. J. 1997. Cloning and characterization of glutamine synthetase from $\mathrm{Col}$ letotrichum gloeosporioides and demonstration of elevated expres- 
sion during pathogenesis on Stylosanthes guianensis. Curr. Genet. 31:447-454.

Talbot, N., Ebbole, D., and Hamer, J. 1993. Identification and characterization of MPG1, a gene involved in pathogenicity from the rice blast fungus Magnaporthe grisea. Plant Cell. 5:1575-1590.

Tu, J. C. 1985. An improved Mathur's medium for growth, sporulation and germination of conidia of Colletotrichum lindemuthianum. Microbiosis 44:87-93.

Van den Ackerveken, G. F. J. M., Dunn, R. M., Cozijnsen, T. J., Vossen, P., Van den Broek, H. W. J., and De Wit, P. J. G. M. 1994. Nitrogen limita- tion induces expression of the avirulence gene avr9 in Cladosporium fulvum. Mol. Gen. Genet. 243:277-285.

Yakoby, N., Kobiler, I., Dinoor, A., and Prusky, D. 2000. pH regulation of pectate lyase secretion modulates the attack of Colletotrichum gloeosporioides on avocado fruits. Appl. Environ. Microbiol. 66:10261030.

Yakoby, N., Beno-Moualem, D., Keen, N. T., Dinoor, A., Pines, O., and Prusky, D. 2001. Colletotrichum gloeosporioides pelB, is an importan factor in avocado fruit infection. Mol. Plant-Microbe Interact. 14:988 995. 